\title{
Cholera outbreak in Baghdad in 2007: an epidemiological study
}

J.M. Khwaif, A.H. Hayyawi² and T.I. Yousif'

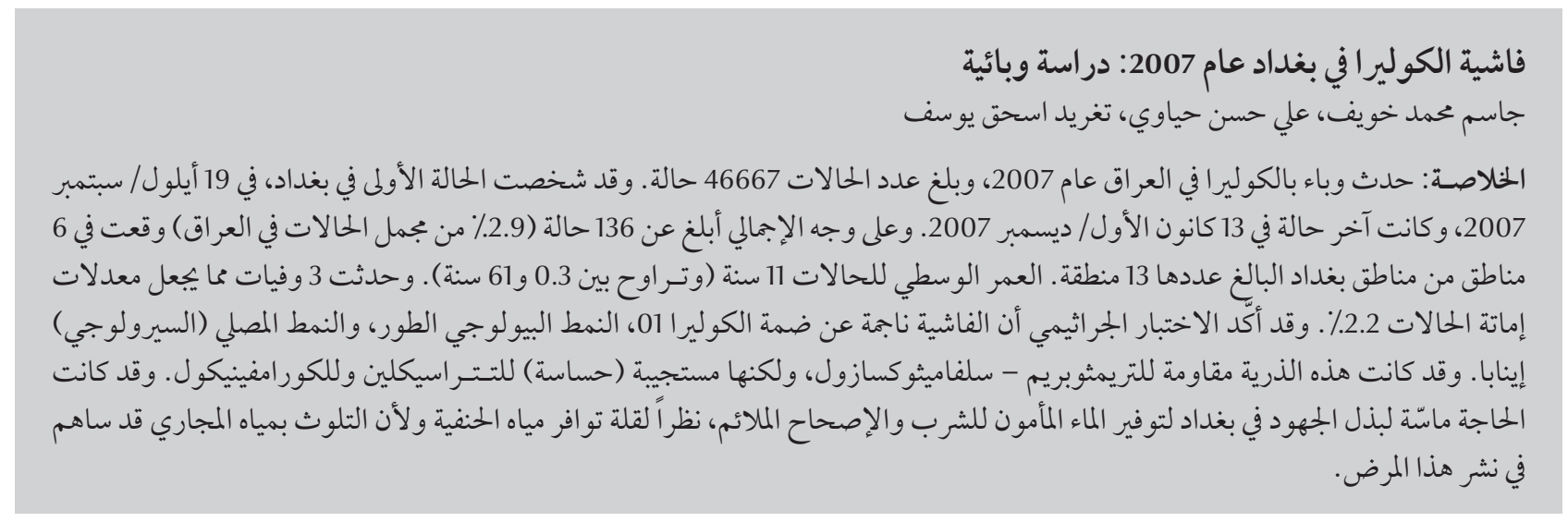

ABSTRACT In 2007 there was an epidemic of cholera in Iraq with 4667 cases. The first case in Baghdad was diagnosed on 19 September 2007 and the last case on 13 December 2007. In all, 136 cases were reported (2.9\% of the country total) in 6 of the 13 districts of Baghdad. The median age of the cases was 11 years (range $=0.3-71$ years). There were 3 deaths giving a case fatality rate of $2.2 \%$. Bacteriological testing confirmed that the outbreak was caused by Vibrio cholerae 01, biotype El Tor, serotype Inaba. The strain was resistant to trimethoprimsulfamethoxazole, but sensitive to tetracycline and chloramphenicol. Efforts are needed in Baghdad to establish safe drinking-water and proper sanitation as limited availabilty of tap-water and sewage contamination probably contributed to the spread of the disease.

\section{Flambée du choléra à Bagdad en 2007 : étude épidémiologique}

RÉSUMÉ En 2007, I'Iraq a connu une épidémie de choléra, avec 4667 cas recensés. Le premier cas observé à Bagdad a été diagnostiqué le 19 septembre 2007, et le dernier le 13 décembre de la même année. Au total, 136 cas ont été signalés dans six des 13 quartiers de Bagdad (2,9\% des cas identifiés dans l'ensemble du pays). L'âge moyen des malades était de 11 ans (fourchette $=0,3-71$ ans). Trois décès ont été constatés, soit un taux de létalité de 2,2\%. Les analyses bactériologiques ont confirmé que cette flambée était due à la présence de Vibrio cholerae 01, biotype El Tor, sérotype Inaba. Cette souche était résistante à l'association triméthoprime sulfaméthoxazole, mais sensible à la tétracycline et au chloramphénicol. Des efforts sont nécessaires à Bagdad pour garantir la disponibilité d'eau de boisson saine et un système d'assainissement adéquat, l'accès limité à l'eau courante et la contamination par les eaux usées ayant probablement contribué à la propagation de la maladie.

${ }^{1}$ Communicable Disease Control Centre Baghdad; ${ }^{2}$ HIV Control Department, Al-Resafa Department of Health, Baghdad, Iraq (Correspondence to A.H. Hayawi: hayawi2004@yahoo.com).

Received: 30/04/08; accepted: 16/07/08 


\section{Introduction}

Cholera is a diarrhoeal disease caused by infection with the bacterium Vibrio cholerae biotype 01 or 0139; both children and adults can be affected [1].

Iraq is at risk of cholera epidemics because it lies on the route of pilgrimage to Mecca and contains a number of holy shrines [2]. Cholera first spread to Basra during the epidemic of 1820 and there were a great number of deaths [2]. The disease also spread to Baghdad, with similar consequences. The disease then completely disappeared from Iraq to reappear again in August 1966 as a part of the 7 th pandemic spread $[3,4]$. Since then occasional outbreaks have continued in Iraq [5] (Figure 1). Cholera became endemic in all governorates of Iraq following the 1991 Gulf Crisis. Rural areas were particularly affected with the high risk period occurring from April to November [6].

In the 1991 outbreak, one-third of the total number of reported cases in Iraq were in Baghdad city, while in the inter-epidemic period 1991-98, Baghdad had a smaller proportion of the total. However, in 1999 the reported cases in Baghdad again represented around one-third of the total reported cases $[7,8]$. From 1999, the reported cases of cholera fell to reach a low of 35

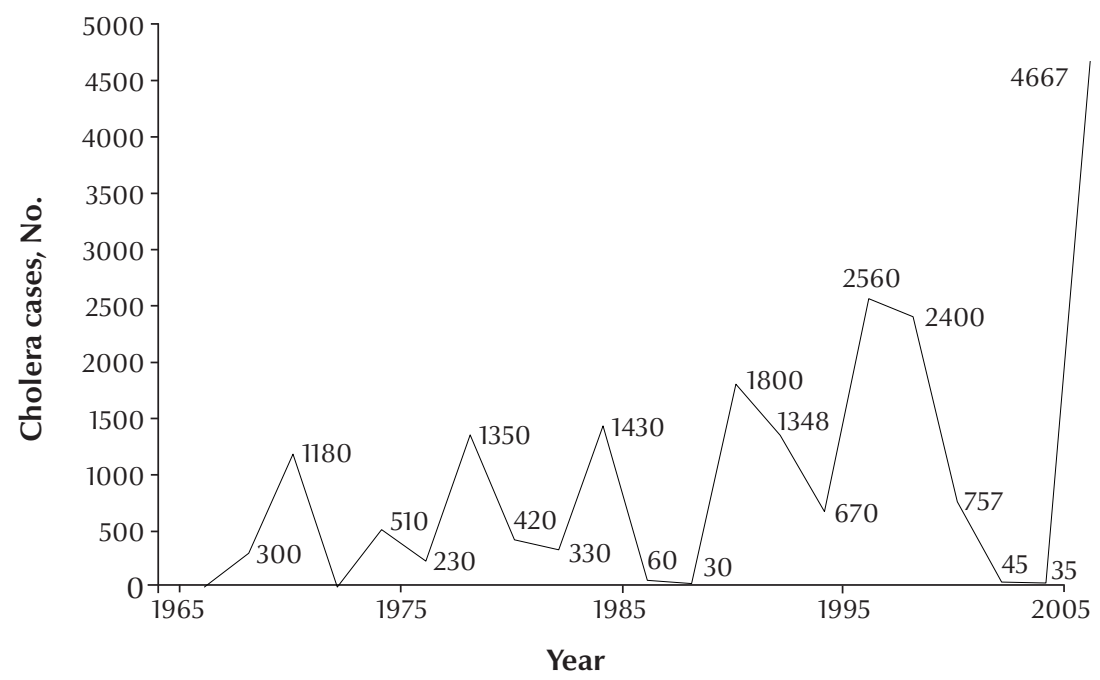

Figure 1 Reported cholera cases in Iraq, 1967-2007 cases in 2005 and in the 3 years prior to 2007 no cases of cholera were reported in Baghdad in the 4-month period September-December.

However, in 2007, a cholera outbreak emerged throughout Iraq. This paper documents the epidemiological situation in Baghdad during this last cholera epidemic.

\section{Methods}

\section{Backgound}

The central province, Baghdad, is the capital of Iraq. It had a population of about 6.5 million in 2007. It is divided by the Tigris River into 2 sides, Al-Resafa to the east and Al-Karkh to the west.

The central area of Baghdad, which is within the boundaries of Baghdad Municipality, is supplied by safe pipedwater through 2 major water projects, 1 on each side; in addition to that, there are many small water plants. The areas outside the boundaries of Baghdad Municipality are supplied with water either from small water plants, which are under the supervision of the Ministry of Municipalities and General Works, or they take their water from tankers, wells or directly from the river.

A few districts in Baghdad are served by an efficient sewage disposal system, some areas posses a sewage disposal net but it is old and inefficient, while most other districts of the city do not even have this sewage disposal net.

Health services are provided by 2 directorates of health $(\mathrm{DOH})$, one on each side of the river. Many primary health care centres (PHCCs) are distributed throughout Baghdad. PHCCs sharing the same geographical locality are connected to a Primary Health Care District (PHCD). Seven of these districts are linked to the Baghdad Al-Karkh $\mathrm{DOH}$ and 6 are linked to Baghdad AlResafa DOH. The population served by Al-Resafa DOH is 3650383 and by Al-Karkh DOH 2937300 . Several general and specialty hospitals on both sides are connected to each $\mathrm{DOH}$.

\section{Case definition}

The Iraqi Ministry of Health $(\mathrm{MOH})$ annually issues and distributes the $\mathrm{Na}$ tional Cholera Control Plan (NCCP) to every governorate. This plan uses World Health Organization (WHO) definition for a cholera outbreak. WHO states that: "a cholera outbreak should be suspected if there is a sudden increase in daily number of patients with acute watery diarrhoea, especially patients who pass the 'rice water stool' typical of cholera". Isolation of $V$. cholerae 01 or 0139 from the stool of any patient with diarrhoea supports the diagnoses of an outbreak.

\section{Case detection}

The NCCP includes procedures for handling samples. Stool samples collected in PHCCs are transported in CaryBlair medium to the nearest hospital. In the hospital laboratory, stool samples collected from both PHCCs and the hospital itself are processed in TCBS (thiosulfate-citrate-bile salts-sucrose agar) medium for diagnosis of $V$. cholerae. Stools found positive for $V$. cholerae are transferred to the Reference Laboratory at the Central Public Health Laboratory, where further analysis is done to confirm the diagnoses, identify the 
specific serotype and carry out sensitivity testing. Each confirmed case is notified to the national Communicable Disease Control Centre in Baghdad.

In an epidemic situation, NCCP strengthens coordination and cooperation between all involved sectors and stakeholders. It also strengthens the surveillance activities, which include: establishing a zero weekly report of diarrhoeal cases; ensuring testing of all cases who meet the stated case definition of cholera in hospitals and diarrhoeal cases attending the PHCCs (routine situation); and maintaining daily routine examination of drinking water by PHCCs for chlorine levels.

\section{The 2007 outbreak}

In the 2007 outbreak in Baghdad, the first case was diagnosed on 19 September 2007. This was a 45-year-old married woman from Al-Madaen district. This case resulted in the activation of the National Cholera Control Committee at the $\mathrm{MOH}$ level and the Cholera Committee at the Baghdad level.

Both Baghdad Al-Resafa DOH and Baghdad Al-Karkh DOH established "rapid response and case detection teams" to start the immediate epidemiological work that included: visiting each diagnosed cholera case at their home; collecting personal data by direct interview; examining the contacts; and assessing the environmental situation (type of water supply and the method of sewage disposal). These data were reported and sent to the Communicable Disease Control Centre in the $\mathrm{DOH}$; these reports have been reviewed and united in a single epidemiological report. The data were analysed using EpiInfo, version 3.3 .

\section{Results}

The total number of reported cases in the 2007 cholera epidemic in Iraq was 4667, of which 136 (2.9\%) were in Baghdad. The first case reported in Baghdad was on 19 September, while the last was on 13 December. No cholera cases had been reported in the same period in the previous 3 years. Five carriers $(0.5 \%)$ were identified among the asymptomatic household contacts of the cholera cases examined. Three patients with cholera died, giving a case fatality rate (CFR) for Baghdad of $2.2 \%$.

The median age of the cases was 11 years (range $0.3-71$ years); $33.1 \%$ of the patients were less than 5 years of age, and cumulatively $44.1 \%$ were less than 10 years (Table 1). Males constituted $49.5 \%$ of the patients, giving a male to female ratio of: 1:1.03.

Out of the 136 cholera cases, 80 (58.8\%) cases were admitted to hospitals while the remaining 56 (41.2\%) were treated as outpatients with either oral rehydration solution (ORS) alone or ORS and antibiotics.

Isolate testing confirmed that this outbreak was caused by $V$. cholerae 01 , biotype El Tor, serotype Inaba. The strain was resistant to trimethoprimsulfamethoxazole, but was sensitive to the commonly used antibiotics tetracycline and chloramphenicol.

Cholera cases were reported in 6 out of 13 districts. The highest number of cases was in Al-Baladiyatt district: 49 (36.0\%) cases giving an attack rate (AR) of 6.2 cases per 10000 . The lowest number of cases was in Al-Dorha district: 1 (0.7\%) case giving an AR of 0.2 cases per 100 000. The highest AR (12.8 cases per 100 000) was in Al-Madean district. There were 4 carriers in $\mathrm{Al}$ Madaen district and 1 in Al-Karkh district. There were 3 deaths reported during the outbreak, 2 in Al-Karkh district and 1 in Al-Madaen district, giving a case fatality rate (CFR) for Baghdad of $2.2 \%$. The overall carrier rate was $0.02 \%$ (Table 2) (Figure 2).

Just over half the cases (76) had tap-water for drinking and daily use, 3 depended on untreated river water for drinking while 57 obtained their water from additional sources (tankers, wells, river) due to a severe shortage of tapwater (Table 3). Less than half (41.2\%) of the patients lived in places served by a sewage disposal net, while $58.8 \%$ lived in places lacking this service. Most patients (94.9\%) had not eaten outside the home in the week prior to onset.

Figure 3 shows the time distribution of cases. The first case was reported in the 38th week of 2007 (ending September 23), but no cases were reported in week 39 (ending September 30); they started to reappear in week 40 (ending October 7). Thereafter cases continued to be reported and reached a peak in week 46 (ending November 18), dropping to 1 case in week 50 (ending December 16). This was the last case in Baghdad of the 2007 outbreak.

\section{Discussion}

The 2007 cholera epidemic was in fact anticipated from the trend of the disease in the previous years and because of the presence of some risk factors and environmental circumstances favourable for the spread of $V$. cholera, such as damaged infrastructure due to multiple crises, limited access to safe drinking

\begin{tabular}{lccc}
\hline \multicolumn{4}{l}{ Table 1 Distribution of cholera cases according to age group } \\
\hline Age group (years) & No. of cases & $\%$ & Cumulative \% \\
0-4 & 45 & 33.1 & 33.1 \\
$5-9$ & 15 & 11.0 & 44.1 \\
$10-14$ & 14 & 10.3 & 54.4 \\
$15-44$ & 45 & 33.1 & 87.5 \\
$45-$ & 17 & 12.5 & 100.0 \\
Total & 136 & 100.0 & \\
\hline
\end{tabular}




\begin{tabular}{lccccc}
\hline Table 2 Distribution of cases, carriers and deaths according to districts in Baghdad \\
\hline District & $\begin{array}{c}\text { Estimated } \\
\text { population }\end{array}$ & Cases & Carriers & Deaths & $\begin{array}{c}\text { Attack rate } \\
\text { per 100 000 } \\
\text { population) }\end{array}$ \\
Al-Baladiyatt & 784587 & 49 & 0 & 0 & 6.2 \\
Al-Madaen & 352890 & 45 & 4 & 1 & 12.8 \\
Al-Resafa & 528826 & 27 & 0 & 0 & 5.1 \\
Al-Sadder & 992000 & 7 & 0 & 0 & 0.7 \\
Al-Karkh & 615062 & 7 & 1 & 2 & 1.1 \\
Al-Dorah & 665688 & 1 & 0 & 0 & 0.2 \\
\hline
\end{tabular}

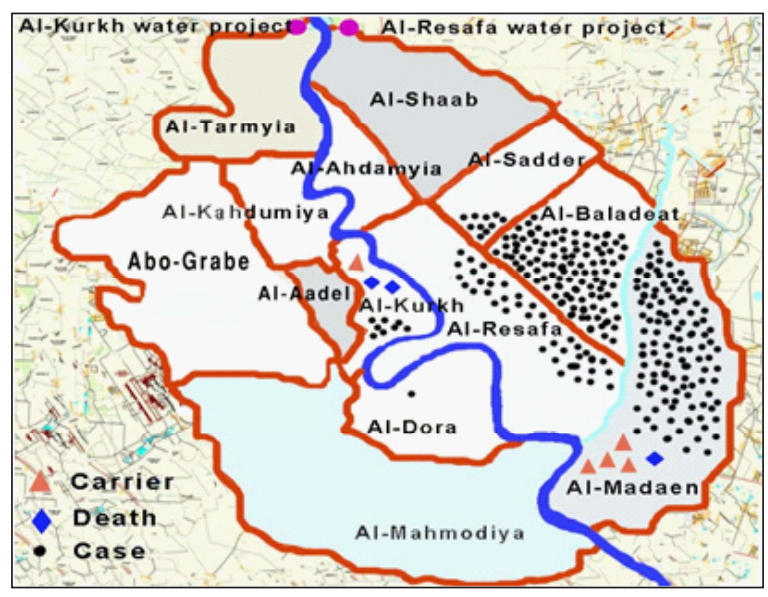

Figure 2 Distribution of cholera cases, carriers and deaths in different districts of Baghdad, 2007

water. Thus there were strategies in place to deal with an outbreak.

Reported cases in Baghdad during thepreviousepidemic(1999)wereabout one-third of the total reported cases in

\begin{tabular}{|c|c|c|}
\hline \multicolumn{3}{|c|}{$\begin{array}{l}\text { Table } 3 \text { Distribution of cholera cases } \\
\text { according to some risk factors }\end{array}$} \\
\hline Risk factor & $\begin{array}{c}\text { No. of } \\
\text { patients } \\
(n=136)\end{array}$ & $\%$ \\
\hline \multicolumn{3}{|c|}{ Source of water } \\
\hline Tap & 76 & 55.9 \\
\hline River & 3 & 2.2 \\
\hline Other $^{\mathrm{a}}$ & 57 & 41.9 \\
\hline \multicolumn{3}{|c|}{ Availability of sewage disposal net } \\
\hline Yes & 56 & 41.2 \\
\hline No & 80 & 58.8 \\
\hline \multicolumn{3}{|c|}{$\begin{array}{l}\text { History of eating out } 1 \text { week prior to } \\
\text { onset }\end{array}$} \\
\hline Yes & 7 & 5.1 \\
\hline No & 129 & 94.9 \\
\hline
\end{tabular}

${ }^{a}$ Tankers, wells, river in addition to tap-water.
Iraq, while in the 2007 epidemic only $3 \%$ of the cases were in Baghdad. This could be related to the causative serogroup Inaba, which prefers moderate the epidemic started in northern areas of Iraq where the highest incidence was also reported. It then reached Baghdad when the temperature became lower and suitable for the strain.

In this outbreak, the carrier rate was relatively low $(0.02 \%)$, which may be related to the difficulties in reaching all the household contacts to be examined. These difficulties resulted from either wrong addresses given by the patients or from of security restrictions. However this carrier rate is similar to that in the 1991 epidemic in Baghdad (0.99\%) [7].

The CFR of $2.2 \%$ in this outbreak is higher than that considered tolerable by WHO (not exceeding 1\%) [1]. It is higher than the CFR in the 1991 temperatures. This could explain why and 1999 epidemics in Baghdad [7,8], and also the CFR in the 2002 epidemic in India[9] and the 1998 epidemic in Ecuador[10]. However, it is lower than the CFR among children in $\mathrm{Ni}$ geria (5.3\%) in the 1996 epidemic [11], Kenya (4\%) in the 1997 population epidemic [12], and the global CFR which was $4.5 \%$ in 1997 and $3.6 \%$ in 1998 [13]. The high CFR in the recent Baghdad outbreak could be explained by the fact that the first death occurred due to acute renal failure as a result of delay in transporting the patient to hospital. The other 2 deaths were in a special facility for mentally retarded and disabled children; one was a 13-year-old child who died before reaching hospital and the other was a 12-year-old child who died after reaching hospital, again because of acute renal failure due to dehydration. After these 2 deaths, medical staff from the nearby hospital and PHCC visited the facility daily. These 2 deaths could have been avoided if there had been a 24-hour clinic for the children at the facility. The facility was also visited by a team from $\mathrm{WHO}$ and both the $\mathrm{MOH}$ and $\mathrm{WHO}$ concluded that intense efforts were required (hygiene, medical attention and sanitation) along with close follow-up to improve the situation in this institution [14].

Usual signs and symptoms of severe dehydration and diarrhoea were seen only occasionally in the 2007 epidemic. About $40 \%$ of cases were mild and treated by ORS with or without antibiotics on an outpatient basis. This rate is lower than that of the 1991 epidemic where $52.3 \%$ of the cases were considered mild [7]. In the 1978 epidemic in Bahrain, only $20 \%$ of the cases were severe and needed hospitalization [15]. This supports the WHO statement that during epidemics, half of the cases can be managed outside hospital with ORS with or without antibiotics [1].

Bacteriological study of all isolates in this outbreak revealed that $V$. cholerae, biotype El Tor, serogroup 01, serotype Inaba was present in all isolates. In the 


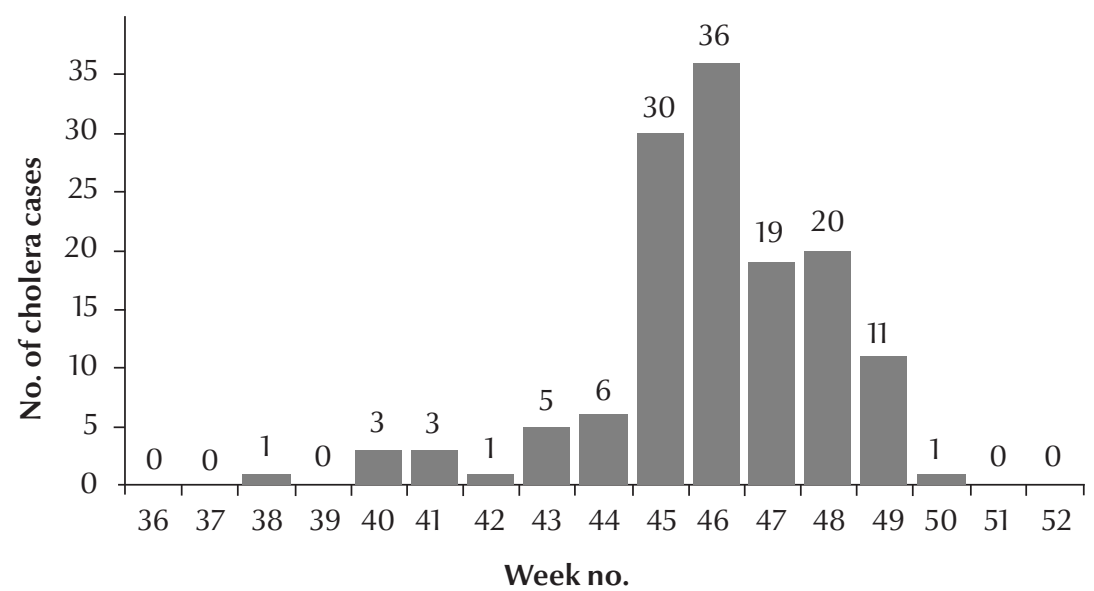

Figure 3 Distribution of cholera cases according to week of the year 2007

1991 epidemic both serotypes Ogawa and NAG were responsible for the reported cases, with a rate of $81.6 \%$ for Ogawa [7]. In the 1999 epidemic serotype Ogawa was responsible for $79.6 \%$ of cases, Inaba $12.1 \%$, parahaemolyticus $2 \%$ and nonparahaemolyticus $2 \%$; serogroup 0139 was found only in 2 isolates [8]. Serotype Inaba was not present at all in the 1991 epidemic, but it was found in the 1999 epidemic at a rate of $12.1 \%$. In the 2007 outbreak all cases were due to serotype Inaba.

The strain of $V$. cholerae in the recent outbreak was resistant to trimethoprimsulfamethoxazole but sensitive to other antibiotics including tetracycline and chloramphenicol. The resistance to trimethoprim-sulfamethoxazole has been reported in other studies [12,16], but in the Indian epidemic in 2000, both 01 and 0139 isolates were sensitive to trimethoprim-sulfamethoxazole [17]. The sensitivity of the cholera strain to tetracycline in the recent epidemic concurs with other studies $[10,12,17]$, but not with a study in western Kenya in 1980 [18]. In the 1999 Baghdad epidemic, $30 \%$ of the cases admitted to hospital were resistant to tetracycline [8]. The sensitivity of the cholera strain to tetracycline in this epidemic could be because the recent outbreak was caused only by serotype Inaba.

One-third (33.1\%) of the cases occurred among those under 5 years of age and $44.1 \%$ among those under 10 year of age. In the 1991 epidemic, the rate among those under 10 year was $30.7 \%$ [6], and in the 1999 epidemic the rate among those under 5 years was $33.4 \%$ [8]. This result is consistent with studies in endemic areas where the highest incidence was among toddlers and children below school age [19-21].

More than half of the cases had access to tap-water for their general usage. Baghdad generally suffers from shortages of tap-water supply, this shortage increases as one descends from northern areas where the 2 major water projects are located. The shortage becomes much more acute during the long, hot Iraqi summer, when the need for water increases. People dealt with this shortage by either using an electric pump or resorting to additional water sources like digging wells (usually water unsafe for human consumption and not bacteriologically tested) and tankers (again unsafe water and not under the control of the central authorities).

A great amount of the infrastructure destruction occurred as a result of the multiple crises suffered by Iraq, which caused great damage to both water-pipes and sewage disposal net. The water-pipes came from different water plants with water fit for human consumption, but further along, away from the plants, the water becomes contaminated by old or damaged pipes or by the sewage stream in areas not served by a sewage net. In addition, the unplanned settlement of immigrant families in certain areas which had no water pipes or sewage disposal nets, forced the inhabitants to obtain water by digging down to the mains pipe and drawing water using devices in an unorganized and incorrect manner, which led to leakage and contamination of the water inside the pipes.

The peak incidence in this outbreak was at week 46 in 2007 (end November 18) after which it steadily decreased to the last reported case at week 50 (end December 16). During the 2007 outbreak, all possible preventive measures were taken to reduce the risk of transmission of cholera. Epidemic preparedness for cholera and surveillance of diarrhoeal disease was intensified in all directions. In addition, the decreasing temperature played a role in containment of the outbreak.

This outbreak was characterized by the high number of cholera cases in those under 5 years of age. The expected contamination of water, aggregation of cases in 1remote districts far removed from main water projects, and the very low history of eating out of the home could lead to a conclusion that this outbreak was most probably transmitted through the water.

Cholera is a preventable disease and can be controlled. What can be learned from the 2007 outbreak is that intensive efforts are needed in Baghdad to establish safe drinking-water and proper sanitation for all people; have laboratory and therapeutic needs available on the spot; and ensure year-round surveillance activities for early detection of cholera cases.

\section{Acknowledgement}

We would like to thank Dr Faris AlLami for his kind revision of this work. 


\section{References}

1. WHO Global Task Force on Cholera Control. Cholera outbreak, assessing the outbreak, response and improve preparedness. Geneva, World Health Organization, 2004

2. Al-Wardi A. Cholera epidemic. In: Social aspects of Iraqi modern history. Baghdad, Matba`at al-adib al-baghdadiyya, 1996:244-4.

3. Benson AS. Cholera. In: Evans AS, Brachman PS, eds. Bacterial infection of humans: epidemiology and control, 2nd ed. New York, Plenum, 1991:207-25.

4. Al-Awqati QS, Mekkiya M, Thmer M. Establishment of cholera treatment unit under epidemic conditions in a developing country. Lancet, 1969, 1:252-3.

5. Weekly situation report on acute watery diarrhoea and cholera in Iraq. Amman, World Health Organization Regional Office for the Eastern Mediterranean, WHO Representative Office in Iraq, 2008 (Sitrep No. 49) , http://www.emro.who.int/iraq/ pdf/Sitrep_48.pdf, accessed 11 January 2010)

6. Communicable disease profile, Iraq. Geneva, World Health Organization, 2003 (WHO/CDS/2003,17) (http://www.who.int/ infectious-disease-news/IDdocs/whocds200317/1profile.pdf, accessed 11 January 2010).

7. Yousif TI. Epidemiological study of cholera outbreak in Baghdad, 1991. [Dissertation]. Baghdad, University of Baghdad, 1993.

8. Al-Abbassi AM, Ahmed S, Al-Hadithi T. Cholera epidemic in Baghdad during 1999: clinical and bacteriological profile of hospitalized cases. Eastern Mediterranean health journal, 2005, 11(1/2):6-13.

9. Phukan AC et al. A cholera epidemic in rural area of northeast of India. Transactions of the Royal Society of Tropical Medicine and Hygiene, 2004, 98(9):263-6.

10. Gabastou JM et al. Caracteristicas de la epidemia de colera de 1998 en Ecuador, durante el fenomeno de "El Nino" [Characteristics of the cholera epidemic of 1998 in Ecuador during El Nino]. Revista panamericana de salud pública, 2002, 12(3):157-64

11. Falade AG, Lawoyin T. Feature of the 1996 cholera epidemic among Nigerian children in Ibadan, Nigeria. Journal of tropical paediatrics, 1999, 45(1):59-62.
12. Shapiro RL et al. Transmission of epidemic Vibrio cholerae 01 in rural western Kenya associated with drinking water from Lake Victoria: An environmental reservoir for cholera. American journal of tropical hygiene, 1999, 60(2):271-6.

13. Cholera 1998. Weekly epidemiological record, 1999, 74(31):25764.

14. Weekly situation report on cholera in Iraq. Amman, World Health Organization Regional Office for the Eastern Mediterranean, WHO Representative Office in Iraq, 2007 (Sitrep No. 38, week 47, 25 November 2007) (http://www.reliefweb.int/ rw/RWFiles2007.nsf/FilesByRWDocUnidFilename/AMMF79YEPU-full_report.pdf/\$File/full_report.pdf, accessed 11 January 2010).

15. Gunn RA et al. Cholera in Bahrain epidemiological characteristics of an outbreak. Bulletin of the World Health Organization, 1981, 59(1):61-6.

16. Ndour CT et al. L'epidémie de choléra de 2004 à Dakar, Sénégal : aspects épidémiologiques, cliniques, et thérapeutiques [Cholera epidemic of 2004 in Dakar, Senegal: epidemiological, clinical, and therapeutic aspects.] Médecine tropicale, 2006, 66(1):33-8.

17. Samal B et al. Epidemic of Vibrio cholerae serogroup 0139 in Barhampur, Orissa. Indian journal of medical research, 2001, 114:10-1

18. Finch MJ et al. Epidemiology of antimicrobial resistant cholera in Kenya and East Africa. American journal of tropical hygiene, 1988, 39:484-90.

19. Bhattacharya SK et al. Cholera in young children in an endemic area. Lancet, 1992, 340:1549.

20. Franco AA et al. Cholera in Lima, Peru correlates with prior isolation of Vibrio cholerae from the environment. American journal of epidemiology, 1997, 146(12):1067-75.

21. Mintz ED, Tauxe RV, Levin MM. The global resurgence of cholera. In: Noah N, O'Mahony M, eds. Communicable diseases epidemiology and control. London, John Wiley, 1998:63-94. 